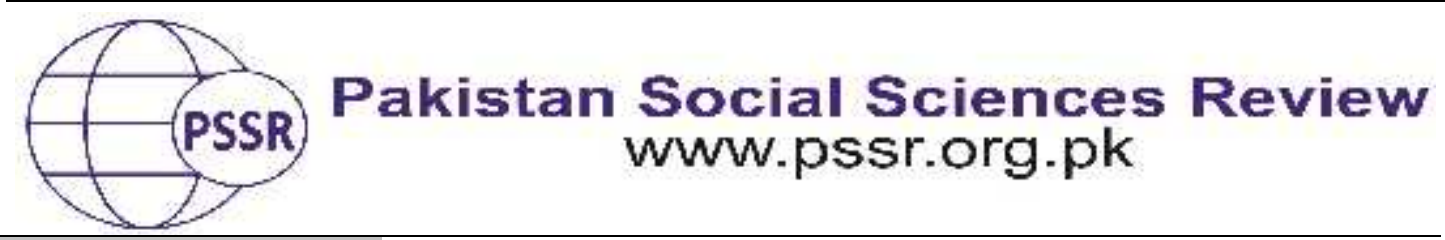

RESEARCH PAPER

\title{
Anglicization of Urdu Language: A Lexico Grammatical Analysis of Urdu Advertisements
}

\author{
Muhammad Waseem ${ }^{1}$ Tasawar Abbas Shah ${ }^{2}$ Adila Hussain ${ }^{3}$
}

1. Ph. D Scholar, Azad Jammu Kashmir University, Muzaffarabad, AJK, Pakistan

2. Ph. D Scholar, University of New Mexico, Albuquerque, NM, USA

3. Ph. D Scholar University of Gujrat, Pakistan, Punjab, Pakistan

\begin{tabular}{|c|c|}
\hline & BSTRACT \\
\hline 1: & $\begin{array}{l}\text { When native languages come in contact with non-native } \\
\text { languages, they absorb lexical items of each other. Urdu and } \\
\text { English languages are pertinent case in this regard. Urdu } \\
\text { language came in contact with English language particularly } \\
\text { after the arrival of British forces in Indo-Pak subcontinent. }\end{array}$ \\
\hline $\begin{array}{l}\text { sements, } \\
\text { zation, } \\
\text { ing, } \\
\text { atical, } \\
\text { c }\end{array}$ & $\begin{array}{l}\text { Anglicization of Urdu language and Urduization of En } \\
\text { language. This study focuses on the lexical borrowing of En } \\
\text { in Urdu advertisements. Data is collected from billboards } \\
\text { signboards. To achieve the targeted aim insights are taken } \\
\text { Kachru's model of world Englishes. Moreover, dictio } \\
\text { (Wiktionary) and online cite www.quora.com is used to finc }\end{array}$ \\
\hline ponding & $\begin{array}{l}\text { Jmology of both English and Urdu words. Ten compound } \\
\text { ords are extracted from billboards and sign boards. These } \\
\text { ords are tested from 'American Heritage English Dictionary' in } \\
\text { der to check whether or not these words are lexically } \\
\text { rrowed from inner circle. Dictionary of etymology explored } \\
\text { e origin and literal meaning of words. The research unearths } \\
\text { markable Anglicization of Urdu language in terms of } \\
\text { vertisement. Syntactic pattern shows that parts of speech are } \\
\text { nnificant attribute of advertising text and noun words are }\end{array}$ \\
\hline @gmai & exical gaps that Urdu cannot meet in \\
\hline
\end{tabular}

\section{Introduction}

Languages are living beings. They take birth, develop and die gradually. Languages affect each other when they come in contact with each other. Contact starts when languages of prestige and power are spread by means of colonization and conquest. British colonies and countries under the influence of English rules have remarkable linguistic impacts on the native language. Even the countries which have been colonies are not free of this influence. Pakistan also falls in the list of these 
countries. Pakistan has been under the control of British regime for almost hundred years. During this period interaction between both nations brought considerable transfer of cultural, religious and linguistic elements. People well aware of English got significant niche in government sectors. Urdu is the mother tongue of Pakistan while English is second and official language and is spoken by privileged class or educated elite class and it has turned into the language of "modern intellectual communication" (Bhatia\& Ritchie, 2006). Such interaction between both nations started to Anglicize the Urdu language from different dimensions.

There are various researches on code-switching, code-mixing and lexical borrowing but every researcher has different area of interest some collected data from news paper or magazine advertisements some investigated code switching among face book users or among youngsters of private school. There is either no or scarce research on billboard or signboard advertisements. The present study discusses the lexical borrowing at grammatical level in Urdu advertisements and tells whether borrowed words come from inner circle or not.

The current study inquires into Anglicization of Urdu language on billboard and signboard advertisements. The research is qualitative in nature while judgmental sampling is employed in the study. Data is collected from Eminabad to Khyali Bypass and Khyali Byapass to Pindi Bypass, Gujranwala, Pakistan. Moreover, an online dictionary "The American Heritage Dictionary of English Language"(Wiktionary, 1993, ed $5^{\text {th }}$ ) by Cookery and another online site www.quora.com is used to find out etymology of both English and Urdu words.Beraj Kachru's model of world Englishes developed in 1985 is used as analytical framework. In this model Beraj Kachru discussed the diffusion of English in terms of three concentric circles the inner circle, the outer circle and expanding circle.

The research unearths remarkable Anglicization of Urdu language. Moreover, the paper uncovers that English words are borrowed lexically in advertising text. Furthermore, syntactic pattern shows that parts of speech are a remarkable attribute of advertising text and noun words are borrowed more. Lexical borrowing is taking place in Urdu advertisements to fill the lexical gaps that Urdu cannot meet in bilingual context of Pakistan. Additionally, the use of English words is considered to be modern and symbol of honor which raises their social status and is taken as civilized language in Urdu ads. Findings shows that Urdu language is the expression of emotions while English language represents logical ideas, therefore, people use Urdu-English mix language to attract consumers. The findings also illustrate that words are borrowed from inner circle to outer circle.

\section{Literature Review}

Lexical borrowing is adoption of vocabulary items from one language to another at grammatical level. Lexical borrowing and mixing language is a matter of great interest as it provides enough data for explanation. Language change and come 
into contact when they follow give and take rule in lexical semantic structure. Today, the Urdu language we use is the amalgam of different languages. English is Linguafranca and is being used almost in every sphere of life. Pakistan is a country of multilingual community and people are able to use even a single sentence in pure Urdu. In different ages researchers had kept themselves busy in finding the reasons of Lexical borrowing, code mixing and different psycholinguistic and sociolinguistic factors that associated with code switching. One such factor which they found is bilingualism that results in Lexical borrowing.

The contact causes lexical borrowing, code switching and code mixing of languages. Borrowing is an adoption of words from one language to another. Borrowing is defined by Gumperz (1982) as the introduction of single words or short, frozen, idiomatic phrases from one variety (i.e. language) into the other. According to deficit hypothesis by Kachru (1994), the lexical borrowing fills linguistic gaps of recipient language and the prime inspiration for lexical borrowing is to cure deficiency particularly in the lexical assets of a language. Stanlaw(1987) noticed that "One important reason for the use of English loanwords is that they provide linguistic tools that individuals can use in personal and highly creative ways. However, Takashi (1997) who analyzed Japanese advertisements did not agree with Stanlaw and claimed that the unusual use of English loanwords in advertisements is just to get attention of the customers and it may promote the mixture of dialect. What is more, after exploring Pakistani newspapers it is observed that in Pakistani English countless words have entered from Urdu and provincial languages of Pakistan (Baumgardner et al., 1993).

Niazi and Khan (2003) studied the use of code switching among teenage students in private schools and described that English is considered as a characteristic of success and high status. Moreover he described that English language has taken a vital position in our general public and youngsters (particularly) think that it's advantageous to utilize both Urdu and English mix. For them it not only beneficial at official level but also raises their social image. Yousaf (2004) investigated that in Pakistan there is a constant shift of English language. A child learn Urdu only at home when he get familiar to Urdu, and as he grows, he has to get the knowledge of English for higher education and for official purposes In present scenario of Pakistan. English has become an important part of our discourse in formal and informal situation.

Also, Anwar (2007) studied on Urdu- English code switching in Pakistani English at the phrase and clause level. He extracted data from Pakistan English magazines and newspapers. His study demonstrates that code switching is a rule governed phenomena. It is not grammarless activity. Moreover, he says that Pakistan English is affected by code switching at the phrase level and clause level. Leung (2010) examined code mixing in print commercials in Hong Kong. The investigation revealed that the utilization of English words in print commercial had been related with advancement and internationalization. 
In Pakistani scenario, the dialect of daily papers mirrors the outlook of individuals of that specific culture (Uzair et al., 2012). He claimed that the borrowings shape Pakistani culture and languages, which had been general element of the daily papers, are found in the dialect of the readers of these daily English newspapers. Further he asked that because of the lexical deviation in these English newspapers there had been developed a new variety of English that is now called Pakistani English. It is change from the norms of standard British English. Rafi (2013) identified the overwhelming use of English words among face book users followed by bilingual Urdu-English. Moreover he found the structural change and implication of Urdu and English language.

Many researchers have done their research on code-switching, Code-mixing and Lexical Borrowing but every researcher has different area of interest some collected data from news paper or Magazine advertisements some investigated code switching among face book users or among youngsters of Private school .No one has conducted research on billboards or signboards advertisement.The present study discuses the lexical borrowing at grammatical level in Urdu advertisements and tells about whether or not borrowed words come from inner circle.

\section{Material and Methods}

\section{Approach}

The research is of qualitative approach in its nature.

\section{Data Collection}

The areas for data collection have been selected from More Eminabad to Khyali Bypass and Khyali Bypass to Pindi Bypass, Gujranwala, Punjab, Pakistan.

\section{Sampling}

Purposive or judgmental sampling is employed to analyze the data.

\section{Theoretical Framework}

Kachru's model of 'World Englishes' the three concentric circles is used as analytic framework which was developed in 1985. In this model Beraj Kachru discussed the diffusion of English in terms of three concentric circles the inner circle, the outer circle and expanding circle. Inner circle and outer circle are directly relevant to the study of an Anglicization of Urdu. Inner circle as a method refers to the historical origins of English where it utilized as native or first language. While outer circle analysis argues that in Pakistan, English spread because of the colonization of Britain in Asia. 


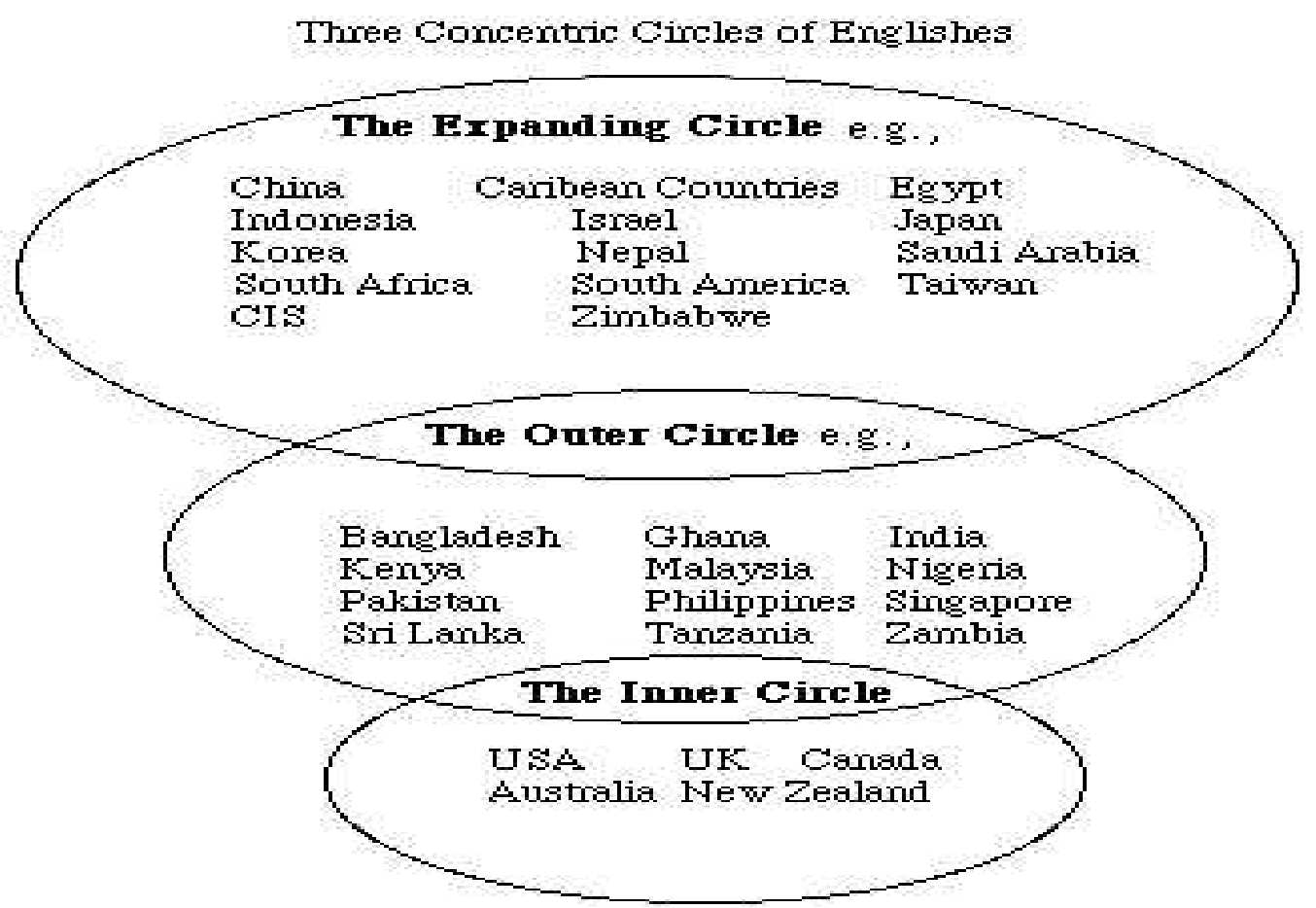

English plays an important role of second language in the multilingual context of Pakistan and is used for official purpose. However the three circle model as a framework explores the English lexical borrowed words shift from inner circle (native language) to outer circle (non-native language).

\section{Data Analysis}

Traits including English lexical borrowing and syntactic pattern of these English lexicons in Urdu advertisements are analyzed. Moreover, the diffusion of English lexical borrowing with semantic content such as parts of speech is investigated in Urdu advertisements.

\section{Biryani House}

Biryani word is a word of Urdu language derived from the Persian language, which was utilized as an official dialect in various parts of medieval India by different Islamic dynasties. One hypothesis is that it began from the Persian word used for rice. Another is that it gets from 'biryan' or 'beriyan', which means fried. Basically it is a dish of 'spicy rice' cooked by using chicken or marinated mutton. The word 'house' is derived from old English 'hus' which means shelter, staying, and building, intended to be utilized as a residence from prototype Germanic 'husan'. It seems to be interconnected with the verb hide. In $14^{\text {th }} \mathrm{C}$ in Gothic 'hus' is used only in the sense of gudhus (temple or god house). In $16^{\text {th }} \mathrm{C}$ the administrative sense is exchanged from the building where body meets meaning gathering of people in theater and place of business. Here it can be said "Biryani House" is a place of business. People write this name in front of the shops to inform people that they can 
get biryani from there. Biryani is purely Urdu word while house is lexical item from British English into Urdu and is most frequently used word on in Pakistani advertisements .Both words are noun. The syntactic pattern of compound words "Biryani House" is (NN).

\section{Caravan Mobile}

Caravan word came from Persian 'karwan' and 'karwanserai' which means 'group of desert travelers' place or inn and then came in English from French 'Caravan'. In 17th century it is used in English for 'vehicle' referred goods and passenger and in the nineteenth century it was utilized for the fundamental kind of second rate class railway carriage. In the late $19^{\text {th }}$ century it is used in the modern sense of 'mobile home'. Now caravan is commonly used word in Urdu as we know Urdu is mixture of different languages. Most of the word in Urdu language came from Persian. The world mobile came in late $15^{\text {th }}$ century it began from middle French mobile and from Latin 'mobiles' mean "easy to move and movable". In 1990s mobile name is associated with a portable phone device which enables users to interact with other users. Caravan mobile name represents the place where mechanic of mobile phone is available to repair mobile phone and other function related to it. Caravan is Urdu word while mobile is borrowed item and both words are noun $(\mathrm{NN})$.

\section{Iftikhar Mechanic}

The word Iftikhar is derived from Persian language which means 'honors, pride and glory'. It is most commonly used name in Muslim countries as well as in Pakistan. Mechanic is originated from late middle English via old French or Latin (mechanical) which means "relating to or requiring mechanical labor" and also from Greek 'mekhanikos' relating to machines or creation,workman brilliant and innovative. However, mechanic is generally used for skillful workers who adjust and repair vehicle motors and other machinery. Iftikhar Mechanic on the sign boards of the shop shows that mechanical labor is available in this shop and customer can repair and mend their vehicle, engine and other apparatus. However, the name Iftihikar is purely Urdu word while mechanic is a borrowing word from English into Urdu. It is frequently used in the advertisements. 'Iftikhar' is a noun while 'Mechanic' is an adjective here the syntactic structure of compound "Iftikharr Mechanic" is (NA).

\section{Sialkot Sweets}

Sialkot is a name of city in Punjab, Pakistan. Raja Sialkot organized this city in 2000 B.C. Before the name of Sialkot the name of the city was 'Iqbal City' and In Indo-Pak the name Sialkot was given to this city during British Government. Sweet word has Germanic origin and it is derived from 'swete' which means pleasurable to the sense, emotions or brain having a charming disposition. In Pakistan sweet is used for 'Mithai' which includes sugar and various ingredients such as milk 
fermented food, and other dry fruits etc. The name 'Sialkot' is purely Urdu word and 'Sweets' is borrowing item from English into Urdu. "Sialkot Sweets' written on signboards is a name given to shop which represent that customers can purchase different kinds of sweets from this shop. The syntactic pattern of compound "Sialkot Sweets" is (NN).

\section{Paan Shop}

Paan is derived from Sanskrit word 'parna'(feather leaf into Hindi paan which is used for betel leaf).It is a psychoactive arrangement of betel leaf with crude tobacco and areca nut. It is necessary piece of Indian culture. Paan word is borrowed from Hindi into Urdu. In Pakistan it is also still served at wedding events, festivals and paan stalls. One of advertisement which catches our attention is of shop advertisement. Shop is derived from old English "Scoppo" means "shed, staltor both for trade" also originated from Proto German 'Skup' means (barn, shed), or in the middle English "eschoppe" word is used which means stall and both. Shop is used to refer to a place or building where things are sold to general public. Shop is lexical adoption in Urdu. 'Paan Shop' appeals the attention of customers who are Paan lovers. The fixation on Paan biting has made it a flourishing and lucrative business industry. A few assortments of betel leaves are developed in farmstead to meet the developing request. Therefore, there are a large number of Paan shops everywhere in Pakistan. The syntactic pattern of 'Paan Shop' is (NN).

\section{Aisha Fabrics}

Aisha means "alive or womanly". It is the name used for women in Muslims and has Arabic origin. The name 'Aisha' is borrowed in Urdu. It is the name of the dearest wife of Muhammad (PBUH), the daughter of first caliph Hazrat Abu Bakar (R.A.). Fabric word is derived from French 'fabrique' and from 'fabricare' which is used in sense of a 'workshop an art structure fabri' taken from word 'faber' which means craftsman who worked in hard material. In English, it is used in a sense of cloth made by weaving or knitting together silk, cotton, or other trades. Fabrics are utilized for making things. For example, garments, sheets and curtains. The structure of 'Aisha Fabrics' is (NN).

\section{Punjab Decorations}

Punjab is a combination of two Persian words Punj (five) and Aab (water). It refers to the land of five rivers. Punjab name was given to a region by Turkish conqueror. It is a geographical region in Indian subcontinent, involving regions of northern India and eastern Pakistan. It is a province of Pakistan. The word decoration is derived from Latin word 'decoratio' or decorare'. It means containing decorating or beautifying material. In English, it is utilized as decoration derived from the word 'decorate' by adding suffix 'ion'. Billboards possess large number of cultural reference. Decoration of houses in wedding events or festivals is a part of Pakistani culture. Advertisement 'Punjab Decoration' signifies cultural reference and conveys a meaning to people who are desirous to decorate their houses, vehicles etc. 
In this shop all the appurtenances related to decoration are available. Decoration is lexicon from English and is used in Urdu. The words 'Punjab' and 'Decoration' are nouns therefore; syntactic structure is $(\mathrm{NN})$.

\section{Akbar Boutique}

The word 'Akbar' is acquired from Arabic word 'Kabir' which means great or powerful. Strikingly a similar word "Kabir" is a Hebrew word and a trait of God. Akbar is one of the most common male names among Muslims as well as in Pakistan. Boutique word is a French word that originated from Provencal 'botiga'. This word is taken from the Italian word "apotheca" meaning store house. Boutique is small store where fashionable jewels garments and other luxury goods are sold. Boutique meaning in Urdu is Dukan but instead of using Dukan Boutique is widely used word in shopping malls markets or even for a small shop. Here, Akbar Boutique shows that they have some expertise in bespoke or uniquely designed clothes for clients. From the compound structure it is found that their syntactic pattern is (NA).

\section{Gandum Store}

Gandum is an Urdu word derived from Malay. The Persian word Gnum (Ganum) was used for Gandum. In English, wheat word is used for Gandum. In Urdu language this word is taken from Persian language. Its main purpose is for flour and for bread stuffs known by different names. Wheat (Gandum) is the most widely cultivated crop across the globe. Store is derived from old French word 'estore' which means 'supplies a fleet army' and it is also taken from Latin word 'Staurum instautum supply. It is also used in Middle English as a store house. The meaning "Place where products are kept available to be purchased" is first recorded in American English. Store is borrowed in its original form in Urdu. Gandum Store demonstrates that it is a place where wheat (gandum) is available to be bought. 'Gandum' and 'Store' are noun. Therefore their syntactic pattern is (NN).

\section{Maher Hotel}

Maher is an Irish surname getting from the Gaelic 'Ó Meachair' which implies the kindhearted or the generous. The predecessor's mers most likely migrated from Iran to India by means of Sindand Rajasthan to Gujarat. They spoke Gujrati language. This cast is originated from the 'mer' community of the Saurashtra, a state of Gujarat in India. They are dominatingly agricultural group. In Pakistan, Maher is a Rajput tribe of Sindhi Muslim. It is located in two provinces Punjab and Sind. The word hotel is originated in Middle English where it was utilized to demonstrate loading. It was taken from the old French word hotel which means a large house or place. Actually both words have their origin from Latin hospital is two words from Latin 'hospes and hospit' signifying people who receive and amuses guests. 'Maher Hotel' is a name given to a place where people are entertained by 
delicious food. Hotel is well-known word spoken in Urdu. The syntactic structure of Maher Hotel is (NN).

\section{Results and Discussion}

The above study reveals that English lexical borrowing is observed in advertisements in bilingual context of Pakistan. English vocabulary is increasing in Urdu language at grammatical level on signboard and billboard advertisements. A noteworthy attribute of advertising text is parts of speech. Noun conducts nominative purpose that advertising text has definite characteristics. The use of adverb contributes to the development of main evaluative attitude to the advertised item to make an emotional way.

From data analysis, it is clear that noun category is borrowed more other than other parts of speech. Analysis of ten compound words illustrate that syntactic pattern of eight is (NN) and two of them are adjective. Nouns are obtained from other language when multilingual people come to know new things and don't have appropriate vocabulary. This is not generally the matter of inaccessibility of words in first dialect. There is an explanation behind loaning words from other dialect anguishing them with the loss of the writers or speaker's own language and that is reputation and prestige.

Kachru (1997) mentioned ideological, cultural and elitist power of English language. Such power is strikingly found in Pakistani advertisement where people turned from Urdu language to English language to create remarkable prestigious effect. English is the dominant language in Urdu-English mixed advertisement and is favored for professional such as Bhatia \& Ritchie (2006) points out that it is a systematic phenomenon which fulfills the innovative needs of bilinguals particularly those necessities that cannot be met effectively and efficiently through single linguistic system such as these words store, shop, house etc are used to fill the lexical gaps or to convey connotation for instance in the example of "Biryani House" house word is used as a rihaish gah which means residence where people live together. If the name of the shop is given 'Biryani Ghar' instead of 'Biryani House' it is not suitable way to convey the actual function of that shop while in English as it is discussed in data analysis house is used for business place.

Another example is 'Gandum Store'. Store meaning in Urdu is 'zakhira krna' and 'Gandum zakhira krna' does not convey a proper meaning to customer that either he should purchase or retained in their possession. On the other hand, the word store gives a proper connotation that store is a place where things are kept to sell. Similarly Paan Shop meaning in Urdu is 'Dukaan' which does not show proper sense while shop word fulfill requirements of that place where this word is used. The use of English language is thought to be the indication of an educated person. The English lexical words such as boutique, mobile, hotel etc among Urdu language are never discouraged. These words give a modern touch. Shopkeeper is used in English words on the fronts of the shops to attract consumers and they consider it a 
civilized language. English language is the best means for the expression of logical ideas while Urdu is used for emotional expression. For instance, most of the people mention the name of their beloved ones and caste names (to show the solidarity of their community in the society) and city name (to show the specialty of the product of their city). For instance, Iftikhar Mechanic, Aisha Fabrics, Akbar Boutique, Maher Hotel and Sialkot Sweets are analyzed above. Iftikhar, Aisha, Akbar, Maher, and Sialkot show the emotional expression of people while mechanic, boutique, hotel, sweets give rational ideas and tell about the function of the shop. The data analysis reveals that English words are borrowed more in Urdu language. Analysis of advertisements reveals that English words are borrowed from inner circle to outer circle.

\section{Conclusion}

The findings of the analysis reveal that English words are borrowed lexically in advertising text of billboards and signboards. Moreover, syntactic pattern shows that parts of speech are a remarkable attribute of advertising text and noun words are borrowed more. Lexical borrowing is taking place in Urdu advertisements to fill the lexical gaps which Urdu language cannot meet in bilingual context of Pakistan. Additionally, the use of English words is considered to be modern and symbol of honor which raises their social status and is taken as civilized language in Urdu advertisements. Findings also disclose that Urdu language is the expression of emotions while English language represent logical ideas, therefore people use UrduEnglish mix language to attract consumers. The findings also demonstrate that words are borrowed from inner circle to outer circle. 


\section{References}

Anwar, B. (2007). Urdu English code Switching: The use of Urdu phrase and Clauses in Pakistani English (A Non-Native Variety). ESP World, 17, pp. 1-14.

Baumgardner,R.J., Kennedy,A.E.H., \& Shamim, F. (Ed). (1993). The English Language in Pakistan. In Baumgardner, R. The Urduaization of English in Pakistan. Karachi: The Oxford Press.

Bhatia, T. K., \& William, C. R. (2006). Handbook of bilingualism. In T. K. Bhatia \& W. C. Ritchie (Ed.), Bilingualism in South Asia (pp. 780-807). Oxford: Blackwell.

Bhatia, T. K., \& William, C. R. (2006). Handbook of bilingualism. In T. K. Bhatia \& W. C. Ritchie (2nd Ed.), Bilingualism in the global media and advertising (pp. 513-546). Oxford: Blackwell.

Cookery. (1993). The American heritage dictionary of the English language (5 ${ }^{\text {thed). }}$ http://en.m.wikitionary.org.

Gumperz, J. (1982). Discourse Strategies. Cambridge University Press.

Kathpalia. S., \& Ong. W. (2015). The use of code- mixing in Indian billboard advertising. World Englishes. Doi: 10.1111/weng.12159.

Kachru, B.B. (1994). The speaking tree: A medium of plural canons. In Georgetown Round Table in Languages and Linguistics (GURT). Washington, D.C.: Georgetown University Press.

Kachru, B. B. (1985). Standards, codification and sociolinguistic realism: the English language in the outer circle. In English in the world: Teaching and learning the language and literatures, edited by R. Quirk and H.G. Widdowson, Cambridge: Cambridge University Press for the British Council

Leung. C. (2010). Code-Mixing in Print Advertisement and its Cultural Implications in Hong Kong. Eru. J. Soc. Sci. 12(3), pp. 417-429.

Niazi, A., \& Khan, S.L (2003). A Study of Language Attitudes and Motivations: EnglishUrdu Code Switching by Teenage Bilinguals in a Private School. FJW Abstracts: Fatima Jinnah Woman University Rawalpindi.

Rafi. S. (2013). Urdu and English contact in an E-discourse: Changes and implications. Gomal university journal of research, 29(2), pp. 79-85.

Stanlaw. J. (1987). Japanese and English: Borrowing and contact. World Englishes, 6(2), pp. 93-109.

Takashi. K. (1997). Japanese Bilingual brand Names. English today, 52, pp. 12-16. 
Uzair. M., Mahmood. A., \& Raja. M. A. (2012). Role of Pakistani English newspapers in promoting lexical innovations. IJPSS, 2(6), pp. 121-186. ISSN: 2249-5894.

Yousaf, F. (2004). Sociolinguistics: Study of Language in the social context. Journal of Research: Faculty of Language E Islamic Studies, 6, pp. 17-25. 